\title{
Waste management policy and citizen participation from the aspect of waste management planning theory
}

\author{
T. Okayama ${ }^{1} \&$ M. Yagishita ${ }^{2}$ \\ ${ }^{1}$ Division of Integrated Research Projects, EcoTopia Science Institute, \\ Nagoya University, Japan \\ ${ }^{2}$ Graduate School of Global Environment Studies, Sophia University, \\ Japan
}

\begin{abstract}
In worldwide measures against environmental problems, the 'participation of all actors and stakeholders' has become of paramount importance. The system of law concerning Japan's environment has also emphasized citizen participation as a long-term target. In addition, laws concerning Japan's waste, which aim towards the construction of a Sound Material-Cycle Society (SMCS) has decreased the use of natural resources as far as possible and reduced the impact on the environment. Waste management laws in Japan have been converted from their status of $1 R$, to $3 R$, that of a sustainable society, for which the participation of citizens and individual stakeholders is essential.

However, there is no legal obligation in the municipality, which could instruct an area how to execute the policy. It is not easy for a society to achieve 'citizen participation and a sound material-cycle society'.

A forum that aimed at "creating a sound material-cycle society based on citizen participation" was held as a social experiment in Nagoya from 2002 to 2005.

By comparing conventional policy-making with participatory policy-making, it was possible to see whether or not participatory policy-making can overcome the weak points of conventional policy-making in terms of policy effectiveness. Keywords: waste management planning, sound material-cycle society, citizens' participation, forum, policy effectiveness.
\end{abstract}




\section{Purpose of the study and definition of "participation" and "partnership"}

'Participation' and 'partnership' are, in principle, what is necessary to manage the worldwide environmental problem. In order to cope with these problems, the general population needs to reform their individual lifestyles countries will be required to reform their national policy. In order to implement such a reform, participation and partnership of all citizens and sectors of society are necessary.

The 'importance of participation of the all stakeholders and citizens' is highlighted even in the Rio declaration of the United Nations Conference for Environmental Development (UNCED) in 1992, under the 10th principle, as follows:

“...Environmental issues are best handled with participation of all concerned citizens, at the relevant level."

Participation of the citizen is addressed as one of the long-term targets in the Japanese Basic Environment Plan, which will be decided in the next years of The Basic Environment Law (1993) that was enforced following the Rio declaration and Agenda 21.

These participation concepts are varied and extensive, and include participation in activities, which preserve the environment and participation in a decision-making and administrative plan. The participation in public decisionmaking is of extreme importance.

Therefore, "the citizen's participation in environmental policy" in this manuscript means participation in the environmental policy decision-making process. Many cases of the citizen participation technique and method have been done at so-called forums in Europe and America, and there are many reviews of the cases that have so far been developed in detail, for example by Renn et al. in 1995 [1], and more recently by Nishizawa in 2003 [2].

The purpose of this study is to make it clear how and what the participation in conventional policy is, and what the issue of conventional policy is, especially from the viewpoint of policy effectiveness, at the same time as comparing conventional policy and participatory policy. The municipal waste management plan in Japan is taken as a specific example case, and it is shown whether or not participatory planning can overcome the weak points of conventional planning from the viewpoint of policy effectiveness. Furthermore, an ideal, method of citizen participation in a waste management plan is proposed by this study.

\section{The Japanese modulo system regarding the waste management}

In Japan, the Basic Environment Law is thought of as the most significant environmental policy. The Fundamental Law for Establishing a Sound MaterialCycle Society (FLESMCS) was formed in 2000, at the same time the Basic Environment plan and Waste Management and Public Cleansing Laws (WMPCL) were amended (Figure 1). 


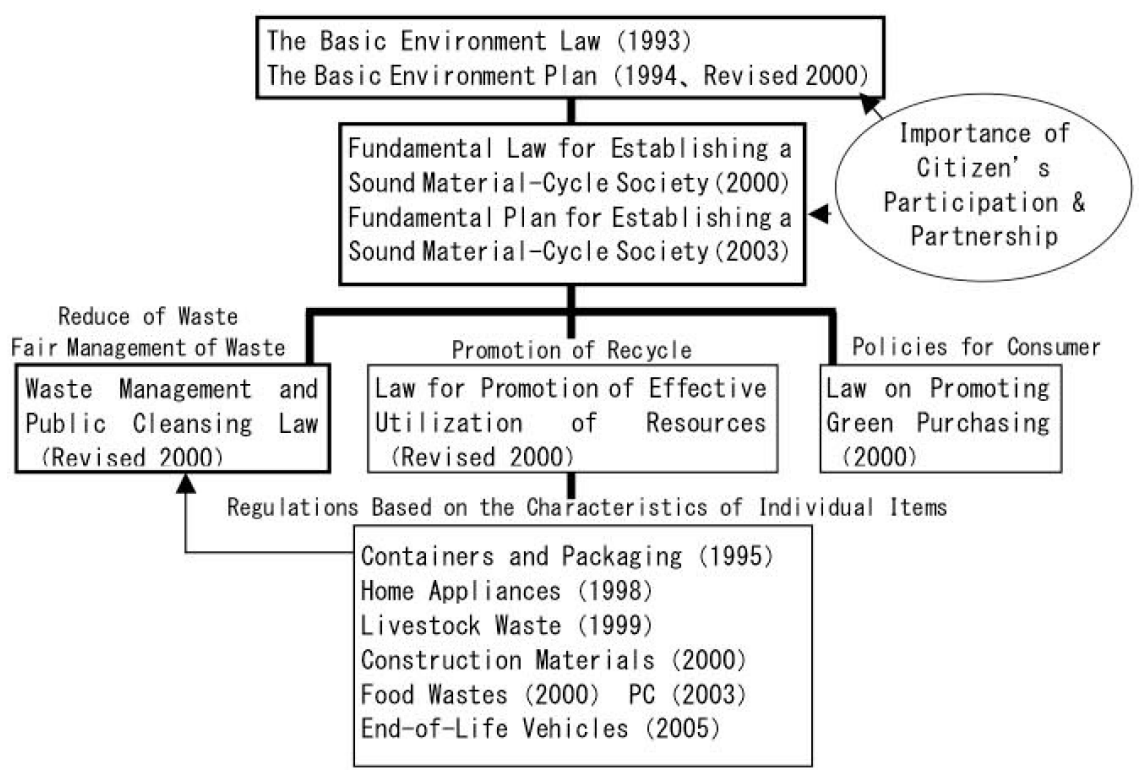

Figure 1: Legislative framework to establish a sound material-cycle society.

The Japanese waste policy was converted from a $1 \mathrm{R}$ (Recycle) policy to $3 \mathrm{R}$ (Reduce, Reuse and Recycle). In Japan, the part of society that this 3R applies to is called a "Sound Material-Cycle Society (SMCS)". For SMCS formation, all sectors of society have to take a second look at their lifestyle and business in order to convert to $3 \mathrm{R}$. The natural resource consumption is suppressed as much as possible, and environmental load should decrease.

Regarding the Tripartite Environment Ministers Meeting between Japan, China and Korea (TEMM), presently "constructing the SMCS" is advanced through $3 \mathrm{R}$ initiatives.

The conduct and partnership of citizens is indispensable in the implementation of $3 \mathrm{R}$, because it is needed for the promotion and procurement of eco-friendly goods and services, for example: mending or reusing old goods, and separating and recycling to reduce the waste. Individual citizens execute these activities. In order to make the $3 \mathrm{R}$ policy more effective, the partnership-type policy should encourage the cooperation and partnership of the citizen. Partnership-type policy, rather than a top-down administrative plan, is an action plan that all stakeholders, including the administration, the citizen and the enterprise make together. With such a partnership, SMCS can effectively be implemented.

Regarding Figure 2, each municipality has a responsibility to dispose of municipal waste (not industrial waste) and therefore has the responsibility of choose the municipal waste management plan to be used. Article 6 of WMPCL requires a decision to be made about a plan. 


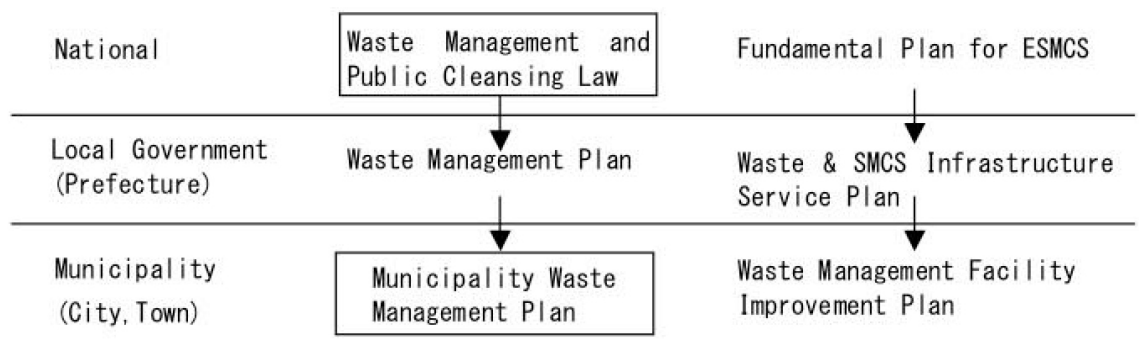

Figure 2: Waste management policy system from national level to local level.

It can be interpreted from The Basic Environmental Plan that WMPCL should be enforced on the basis of being a fundamental plan for establishing an SMCS. However, the only condition is that the waste is processed on the basis of WMPCL, and that the resource should be recycled on the basis of FLESMCS, so in other words, although the target of WMPCL is the correct processing of waste, there is little stipulation regarding SMCS formation. This legal technicality in the municipal waste management plan, which aims to form an SMCS and to keep partnership of all sectors is considered, strictly speaking, as going beyond the necessary function of a municipal waste management plan. Because participation cannot be legally forced, $3 \mathrm{R}$ is not stipulated sufficiently in the municipal waste management plan, and the plan has not become a partnership. In addition, traditionally in the Japanese indirect democracy system, the administration has the main decision-making powers. The opportunity for citizens and enterprises to participate in decision-making is basically limited to elections and in forming public opinion. Recently, the administration has requested opinions from citizens regarding policy-making and has encouraged public comment, which was institutionalized in 1999, questionnaires and candidacy to conference members are sometimes used. However, participation is very limited in the decisionmaking process.

\section{Cases of participatory planning in Japan}

Current details regarding the participation in international environmental policy were shown in Section 1. Regarding Japanese waste policy, as shown in Section 2 , it is thought that in order to convert the conventional waste policy into the much more effective SMCS formation policy (i.e. 3R policy), participation and partnership of stakeholders are necessary. In addition, deciding on a location for the final disposal place and its construction becomes difficult, local finance becomes tight; agreement formation and citizen participation are encouraged. The citizen's understanding and participation are indispensable in such a difficult situation. When experiencing this kind of status, there seem to be some cases where citizens mainly participate in the process of waste management planning. In Aichi prefecture in Tsushima city (2003), Nisshin city (2004) and Mie prefecture Kuwana city (2005), through NGO coordination, citizens decided on a waste management plan. In this case, it was possible for the administrative plan 
to be agreed with the citizens (Hirose et al. [3]), but this plan did not come about as a result of legal obligation, which is stipulated in article 6 of WMPCL, the citizens made the decision instead. The plan was already in place with the main administrative leadership, but the citizens' plan followed the former plan, which basically concerned the decision-making process and the planned contents.

As a pilot case, policy-making was trialled at a forum in Aichi prefecture in Nagoya city from 2002 to 2005 . The purpose of this social experiment was to see whether citizens would positively grasp the concept of an SMCS and be able to make SMCS policy themselves without being restricted by legalities. If it were to work, it was expected that this policy would be more effective than conventional policy (Yagishita et al. [4]). In this paper, this experimental case is called 'participatory planning'.

\section{The difference between the conventional planning and participatory planning}

Figure 3 shows the processes of these two types of planning.

If a conventional type plan is selected, the process will take place as outlined on the left in Figure 3. The foundation of the plan is conceptual planning, the creation of a framework, and the basic planning process. The conceptual planning of municipal waste management is the point at which it is possible to incorporate some specific concepts of general civil planning, which sets the target, purpose and method for carrying out the policy. This is very closely connected to the basic plan, which decides on the location of facilities at each stage of development in order to further the concept of the plan.

At the basic planning phase, the quantity of waste, the quantity of resource material for collection and the final disposal quantity are concretely identified as the targets. These targets are set on the basis of objective data, including evaluations of the present condition, current land use, social status and the amount of waste, resource amount and amount within a year of Business as Usual (BAU). The targets and goals of plans are usually set safely inside the municipality's waste processing ability, even if it is decided from a political aspect first (which is rare). Furthermore, at roughly the same time as the target is set, concrete measures such as compilation of a list of items to separate; collection of resources and distribution of a list of facilities and services for recycling is put together.

Sometimes the municipality requests citizen opinion and public comment concerning the output of the basic plan. During the conceptual planning and the basic planning phases, the planning process is conducted and advanced through conferences. Specialist forms mainly depend upon the municipality. Recently, this conference has included some citizens who have responded as a result of a desire to voice their opinion. For example, in the case of Tsushima city, all members of the conference were citizens offering their opinions. The above is an explanation of conventional planning. 


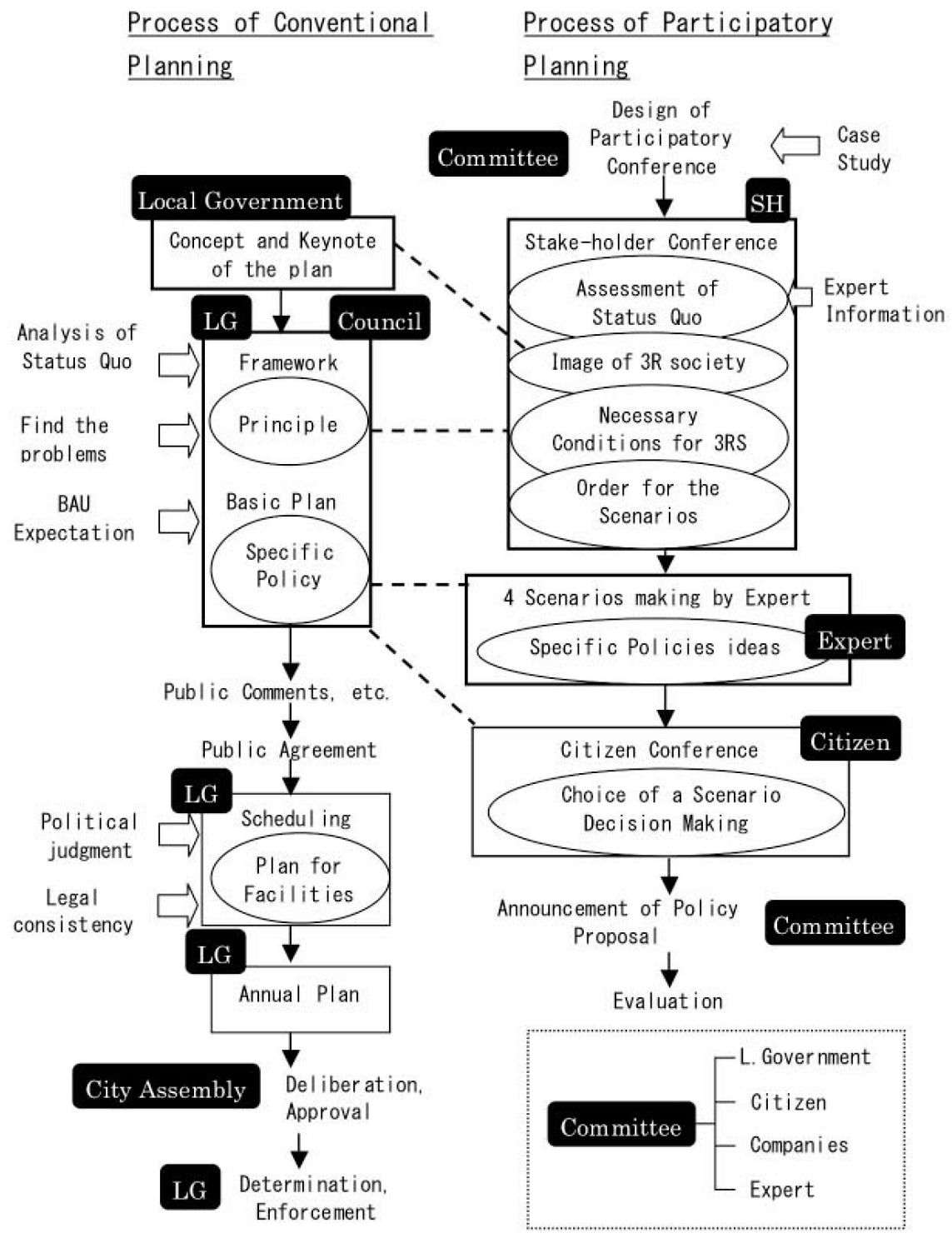

Figure 3: Process of model planning, conventional plan and Participatory plan.

On the other hand, on the right hand side of Figure 3, participatory planning is shown. When planning in this way, 'the Committee for the Forum for Creating a Sound Material-Cycle Society based on Citizen participation' (below, committee) was organized first, and it became the management parent for this forum. Committee members are the stakeholders, the specialists in waste 
management, Nagoya City, and the citizens. On this committee, first of all the method of participatory conference was examined.

Figure 4 shows the concept of participatory planning. It first became clear what the stakeholder image of Nagoya becoming SMCS was, and what the necessary conditions and composition requirements of SMCS would be. Secondly, the plans to transform Nagoya into an SMCS were examined. Before making scenarios, the 'order', which would influence the design of the scenarios was extracted. Finally, one scenario was selected. The committee designed the hybrid-type forums: the stakeholder meeting first and the citizen meeting second.

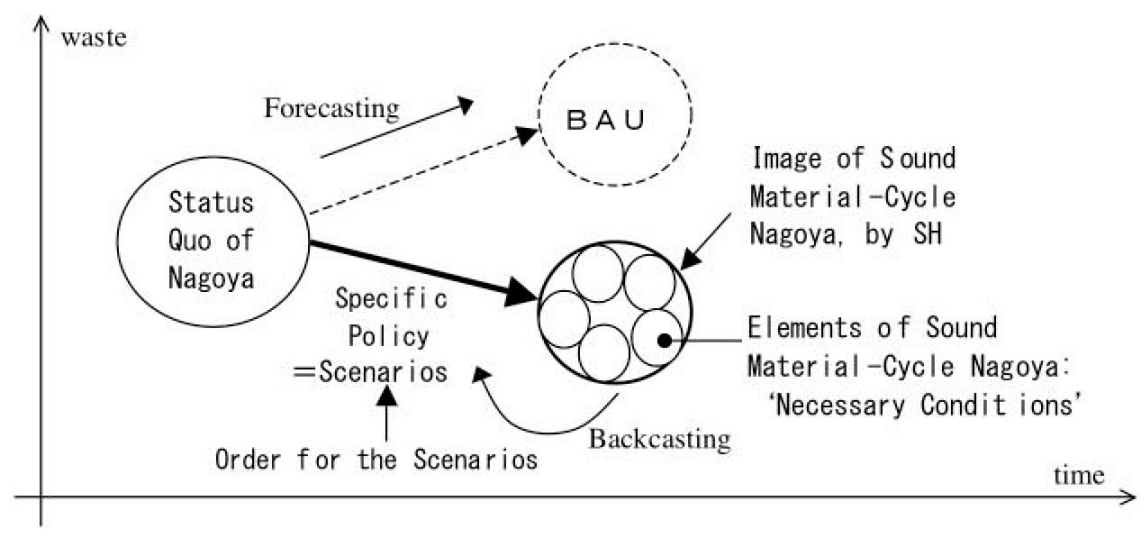

Figure 4: The idea of backcasting planning.

At the stakeholder meeting, the stakeholders firstly evaluated Nagoya city's waste reduction policy from the point of view of the status quo of waste management. They also discussed and decided upon the index for evaluation. This index was set by the necessary conditions and element requirements of SMCS, for example: 'the mechanism of 3R', 'everyone carries out responsibility', 'the person who endeavours is rewarded' and 'communication and consensus' etc. These requirements attach importance to a person's state and sense rather than to physical flow and the environmental load. Next, the stakeholders decided upon the order for creating the scenario. On receiving this order, the specialists created four scenarios.

The committee continuously redesigned the citizens' meeting. The participants of this meeting were extracted at random from the Nagoya City electoral roll, and 16 people gathered. The citizens' meeting discussed the scenario six times and voted twice. One scenario was finally selected, partly revised, and announced as a 'proposal'. The above is an explanation of the method of participatory planning.

Table 1 shows the basic philosophy of the waste management plan and its title.

Nagoya City's plan is used as an example of a conventional plan. The plans of other cities do not greatly differ from this plan. The basic philosophy of Nagoya City's plan is 'administration, citizens and enterprise partnerships'. The 
behaviour of the administration, the citizens and the entrepreneur is being written in a concrete measure. For instance, Nagoya City is requesting its citizens to be greener. Yokohama City has decided that the role of the city is to coordinate citizens and enterprise partnerships. On the other hand, 'participation of all sectors' and 'impartial load' are assumed to be the most important philosophies because of the SMCS construction.

Table 1: $\quad$ Basic philosophy of waste management plan and title of plan.

\section{Nagoya (Participatory)}

[Title] SMCS that is created with effective separation and eco-friendly goods

-Done based on the partnerships and impartial loads of all people who act in Nagoya-

[Basic philosophy]

- Continuous action is most important for the achievement of an SMCS, so that all people who live in Nagoya share equal responsibility.

- For the achievement of the SMCS, "The producer must make the effort to produce eco-friendly goods and to use the recycling system, to reduce waste as far as possible" and "thoroughness in effective waste separation by the citizens" should be set as a prop.

\section{Nagoya City (Conventional)}

[Title] Challenge for SMCS

[Basic philosophy] Challenges for SMCS and Sustainable Society, EcoPartnership for SMCS

Table 2 shows the target of the plan. The plan based on WMPCL has been decided upon to show the amount of the target of the waste processing from the data like the situation of waste discharge, BAU and the target fiscal year.

Table 2: $\quad$ Amount in standard year and target amount of plan (1,000ton).

\begin{tabular}{|l|c|c|c|c|c|}
\hline \multirow{2}{*}{$\begin{array}{l}\text { Type of } \\
\text { planning }\end{array}$} & \multicolumn{2}{|l|}{ Standard Year } & \multirow{2}{*}{$\begin{array}{l}\text { BAU } \\
\text { Target amount }\end{array}$} \\
\cline { 2 - 6 } \cline { 5 - 6 } & Discharge & Land-fill & Discharge & Discharge & Land-fill \\
\hline Participatory & - & - & - & - & - \\
\hline Conventional & 1084 & 150 & 1200 & 1080 & 20 \\
\hline
\end{tabular}

However, the participatory plan has no numerical target amount. Reading the "proposal", the target of a participatory plan is written below. These targets are: partnership among all sectors of Nagoya and mechanisms, which aim at achieving a new society. The environmental impact and the cost expected as a result of this policy are just fixed for referral. The differences mentioned above are summarized in Table 3 . 
Table 3: $\quad$ Features of two types of planning.

\begin{tabular}{|c|c|c|}
\hline & Conventional Planning & Participatory Planning \\
\hline \multirow{2}{*}{ 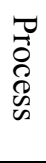 } & Planning process is fixed. & $\begin{array}{l}\text { Designed by participants (committee) } \\
\rightarrow \text { process conducted by citizen }\end{array}$ \\
\hline & $\begin{array}{l}\text { The plan ( output) partially } \\
\text { reflects citizens' opinions. }\end{array}$ & $\begin{array}{l}\text { The output from the forum becomes the } \\
\text { plan. }\end{array}$ \\
\hline \multirow{4}{*}{ 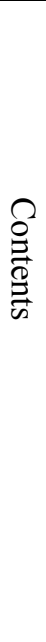 } & $\begin{array}{l}\text { Forecasting } \\
\text { The target is set forecasting } \\
\text { the future from the current } \\
\text { state. } \\
\text { Using BAU }\end{array}$ & $\begin{array}{l}\text { Backcasting } \\
\text { The target is not expressed by the fixed } \\
\text { quantity index. } \\
\text { Moreover, it is not a target led by BAU } \\
\text { either. }\end{array}$ \\
\hline & \multirow{2}{*}{$\begin{array}{l}\text { The target is expressed by } \\
\text { the fixed quantity index. } \\
\text { "Partnership" and } \\
\text { "fairness"etc. are just notes. }\end{array}$} & $\begin{array}{l}\text { The quantification index of the amount } \\
\text { waste etc. is a value of the result of the } \\
\text { policy. It was fixed as verification data. }\end{array}$ \\
\hline & & $\begin{array}{l}\text { "Fairness" is the most important. } \\
\text { Fairness and partnership becomes the } \\
\text { target of plan. }\end{array}$ \\
\hline & $\begin{array}{l}\text { The administrative body } \\
\text { systematizes a necessary } \\
\text { measure for itself. } \\
\text { It is not easy to become } \\
\text { partnership type. }\end{array}$ & $\begin{array}{l}\text { All of actors' behavior is committed. } \\
\text { This is agreed on among actors. } \\
\text { Partnership type }\end{array}$ \\
\hline
\end{tabular}

\section{Conclusion}

In order to increase the effectiveness of the plan, 'understanding and agreeing on the policy' and 'commitment to acting to the policy' are indispensable. However, there is no opportunity for citizens to participate in conventional waste management planning because the waste management plan is an administrative plan, and an administrative plan must be one that the administration decides upon. However, the administration has requested to go beyond the limit of an administrative plan to a waste management plan and an SMCS policy, which require participation and partnership from its citizens. This creates a dilemma for the administration, which creates a weakness and directly impacts upon policy effectiveness. If it is assumed that conventional planning in Table 3 has its weak points, the new participatory method should be able to overcome them.

Therefore, even if it cannot obtain legal proof to make plans and policies by forum in the present system, it has the means for each municipality to hold a participatory forum and make the partnership-type policy.

The part of administration in the plan is assumed to be a conventional waste management plan, then concerning the citizen and the enterprise, the plan also become their action plan which they committed. 


\section{References}

[1] Renn, O. Webler, T. and Wiedermann, P., Fairness and Competence in Citizen Participation; Evaluating Models for Environmental Discourse, Dordrecht, The Netherlands: Kluwer Academic Publishers, 1995.

[2] Nishizawa, M., The "Stick-in" Nature of Citizen Deliberation for Technology-Environmental-and Health-Risk Management in Social Environment: Case from Germany, Dissertation collection of Social Technology Study, Social Technology Study Society, Vol.1, pp.133-140, 2003.

[3] Hirose, Y. Shoji, T. and Asai, N., What Participatory Waste Management Plan is needed to be accepted by Citizens -Case Study from Tsushima City-, Proceedings of the $16^{\text {th }}$ Annual Conference of the Japan Society of Waste Management Experts, pp.186-187, 2005.

[4] Yagishita, M. et al, Final Report of the Study for Creating a Sound Material-Cycle Society Based on Citizens' Participation, (temporary), 2006. 